Article

\title{
Co-Immobilization of Superoxide Dismutase with Catalase on Soft Microparticles Formed by Self-Assembly of Amphiphilic Poly(Aspartic Acid)
}

\author{
Siyu Mao ${ }^{1}$, Rong $\mathrm{Li}^{1}$, Wenchen Wang ${ }^{1}$, Wei Feng ${ }^{1, *}$ and Peijun $\mathrm{Ji}^{2, *}$ \\ 1 Department of Biochemical Engineering, Beijing University of Chemical Technology, Beijing 100029, China; \\ maosiyu420@outlook.com (S.M.); lirong410@outlook.com (R.L.); wangwenchen420@outlook.com (W.W.) \\ 2 Department of Chemical Engineering, Beijing University of Chemical Technology, Beijing 100029, China \\ * Correspondence: fengwei@mail.buct.edu.cn (W.F.); jipj@mail.buct.edu.cn (P.J.); \\ Tel.: +86-010-64446249 (W.F.); +86-010-64423254 (P.J.)
}

Received: 14 June 2017; Accepted: 17 July 2017; Published: 19 July 2017

\begin{abstract}
Through genetic engineering technology, catalase (CAT) and superoxide dismutase (SOD) have been separately fused to an elastin-like polypeptide (ELP). Thus, the enzymes can be purified through phase transition. Hexadecylamine-modified poly(aspartic acid) (HPASP) is able to self-assemble, forming soft microparticles. The HPASP microparticles were used to co-immobilize SOD-ELP and CAT-ELP through amidation reaction. Circular dichroism (CD) confirmed that the secondary structures of the co-immobilized enzymes have been preserved. Fluorescence spectra showed that the co-immobilized enzymes exhibited a higher stability than the free enzymes. Dismutation of superoxide by superoxide dismutase (SOD) generates hydrogen peroxide. By using the co-immobilized enzymes (SOD-ELP/CAT-ELP@HPASP), the generated hydrogen peroxide of SOD-ELP can be decomposed in situ by CAT-ELP. Activity assay results demonstrated that the superoxide anion $\left(\bullet \mathrm{O}_{2}{ }^{-}\right)$scavenging ability is $63.15 \pm 0.75 \%$ for SOD-ELP/CAT-ELP@HPASP. The advantages of the approach of enzyme co-immobilization include the fact that the soft support HPASP itself is a polypeptide in nature, the stability of immobilized enzymes is improved, and a high activity has been achieved. Potentially SOD-ELP/CAT-ELP@HPASP can be applied in the cosmetic industry.
\end{abstract}

Keywords: superoxide dismutase; catalase; amphiphilic poly(aspartic acid); co-immobilization

\section{Introduction}

Superoxide, peroxide, and hydroxyl radical are main components of reactive oxygen species (ROS), and are formed during oxygen metabolism [1]. ROS are involved in the progression of aging as well as neurodegenerative diseases, vascular and cancer diseases, and diabetes [2]. Reactive oxygen species (ROS) take part in different chemical reactions with proteins, leading to fragmented and cross-linked proteins [3]. Overproduced ROS by infiltrated inflammatory cells in the intestinal mucosa may amplify the inflammatory response, trigger mucosal injury, and accelerate mucosal ulceration in the pathogenesis of inflammatory bowel disease [4].

Superoxide dismutase (SOD) is a metalloenzyme [5], it can catalyze the dismutation of superoxide anion radicals into hydrogen peroxide and molecular oxygen, and the evolved $\mathrm{H}_{2} \mathrm{O}_{2}$ may be decomposed into water by catalase or reduced to hydroxyl radical. SOD is considered as the first line of defense against oxidative stress. The enzyme has antiaging, antiviral, and anti-inflammatory effects $[1,2,6]$. SOD has been widely applied in the cosmetics, pharmaceutical, and food industries [6]. 
Investigations have been carried out to overcome the poor stability behavior of SOD. Stability is an important requirement for commercial SODs, as denaturation is the main reason of enzyme inactivation. Therefore, the stabilization of SODs has been paid much attention. Superoxide dismutase was loaded in biodegradable nanoparticles [7]. Nanostructured lipid carriers have been proven to have a high capacity to scavenge free oxygen radicals [8]. Various nanoformulations of resveratrol in phospholipid vesicles have been investigated for their antioxidant activity [9]. Cerium oxide nanoparticles/nanoceria emerged as a potent artificial redox enzyme [10]. Antioxidant enzymes were encapsulated in nano-carriers in order to increase the half-life and thus the efficacy of these enzymes [11-13]. Liposomes have been extensively investigated for the encapsulation of SODs, superoxide dismutase entrapped in long-circulating poly(ethyleneglycol) (PEG)-liposomes [14], liposomal formulations of $\mathrm{Cu}, \mathrm{Zn}$-superoxide dismutase [15], superoxide dismutase entrapped in liposome for oral administration [16], the entrapment of superoxide dismutase into mucoadhesive chitosan-coated liposomes [17]. Poly(ethylene glycol) (PEG) has been conjugated to SOD to improve the enzyme stability and solubility. A variety of coupling reagents, including phenyl chloroformiate [18], cyanuric trichloride [19], and carbonyl diimidazole [20], have been used for the conjugation. The PEGylation did not have a significant effect on the SOD activity, PEG-SOD was generally well tolerated and appears promising in improving outcomes after severe head injuries [21]. Superoxide dismutase was modified to various degrees by reaction with copolymers poly(N-vinyl pirrolidone) with high retention of enzymatic activity [22]. Pluronics have also been conjugated to SOD, the conjugate effectively scavenged xanthine oxidase/hypoxanthine-derived $\left(\bullet \mathrm{O}_{2}{ }^{-}\right)$[23]. To improve the activity of superoxide dismutase and its stability, superoxide dismutase and peroxidase were immobilized in sol-gel glasses [24], and were entrapped in poly(lactide-co-glycolide) microspheres [25].

In this work, to improve the stability and enhance the activity of SOD, amphiphilic poly(aspartic acid) was used as soft support to co-immobilize superoxide dismutase and catalase. The stability and activity of the immobilized enzyme was investigated.

\section{Results and Discussion}

\subsection{Purification of the Fusion Enzyme}

Elastin-like polypeptides (ELPs) are a kind of artificial polypeptides. With ELPs as tags, enzymes can be purified through reversible phase transition, and enzyme purification process can be simplified [26]. Herein the elastin-like polypeptide (ELP) has a molecular weight of $23.7 \mathrm{kDa}$. The ELP polypeptide was fused to the enzymes superoxide dismutase (SOD) and catalase (CAT). Figure 1 shows that the fusion enzymes SOD-ELP and CAT-ELP have been purified with a high purity, and that the contaminants can be neglected. The ELP segment functions to purify the fusion enzyme SOD-ELP through phase transition method [26]. The result in Figure 1 shows that the ELP segment is appropriate for purifying the fused enzyme. Hence it is not necessary to increase the length of ELP. The corresponding sodium dodecyl sulfate polyacrylamide gel electrophoresis (SDS-PAGE) for SOD and CAT is shown in Figure S1 (see Supplementary Materials). 


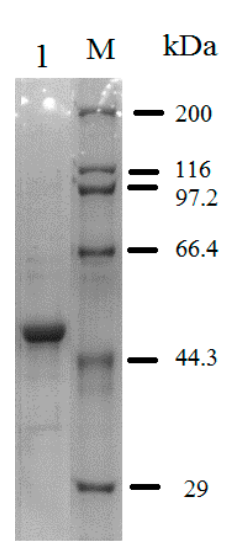

(a)

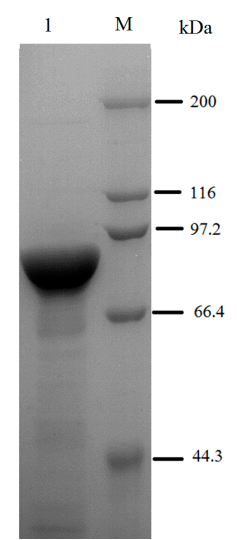

(b)

Figure 1. Analysis of purified SOD-ELP (a) and CAT-ELP $(\mathbf{b})$ by sodium dodecyl sulfate polyacrylamide gel electrophoresis (SDS-PAGE). Lane M: molecular mass marker (KDa); Lane 1 is for the purified proteins. SOD: superoxide dismutase; CAT: catalase; ELP: elastin-like polypeptide.

\subsection{Immobilization of SOD-ELP and CAT-ELP on HPASP}

The hexadecylamine-modified polyaspartic acid (HPASP) formed microclusters in aqueous solutions (Figure 2a). Through the reaction between the carboxyl groups of HPASP and amino groups of the enzymes, the two enzymes SOD-ELP and CAT-ELP were co-immobilized on HPASP. SOD-ELP/CAT-ELP@HPASP also exhibited micro-size clusters (Figure 2b). To directly observe the co-immobilized enzymes, SOD-ELP was labelled with fluorescein isothiocyanate (FITC) and CAT-ELP was labelled with tetramethylrhodamine-6-isothiocyanate (TRITC). FITC-labelled SOD-ELP was immobilized on HPASP and the conjugate exhibited green color (Figure 3a), and TRITC-labelled CAT-ELP exhibited red color after immobilization on HPASP (Figure 3b). When FITC-labelled SOD-ELP and TRITC-labelled CAT-ELP were co-immobilized on HPASP, the conjugate exhibited yellow color due to the overlap of the green and red color (Figure 3c). The confocal images confirm the simultaneous co-immobilization of the two enzymes on HPASP. Based on the fluorescence intensity of green and red colors, as well as the fluorescence intensity of yellow color, the weight ratio of SOD-ELP to CAT-ELP was 1:0.95. The enzyme co-immobilization was further confirmed by the FTIR spectra in Figure 4 for HPASP and SOD-ELP/CAT-ELP@HPASP. The peak at $3295 \mathrm{~cm}^{-1}$ is due to the O-H and N-H stretching vibration. The peak at $2913 \mathrm{~cm}^{-1}$ is due to the C-H stretching vibration- $\mathrm{CH}_{2}$ from hexadecylamine. After enzyme immobilization, the spectrum exhibited a strong band at $1645 \mathrm{~cm}^{-1}$, which was assigned to the vibration of the carbonyl group $(C=O)$ from the enzymes $[27,28]$.

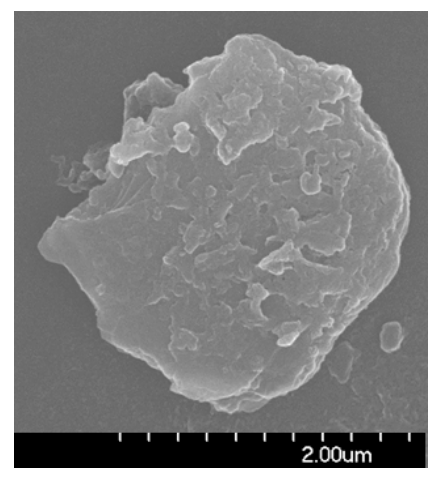

(a)

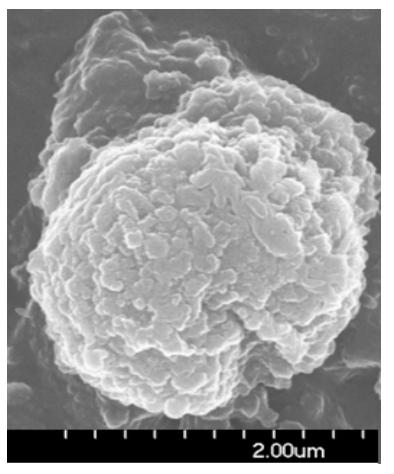

(b)

Figure 2. Scanning electron microscopy (SEM) images. (a) hexadecylamine-modified polyaspartic acid (HPASP); (b) two enzymes immobilized on HPASP (SOD-ELP/CAT-ELP@HPASP). 


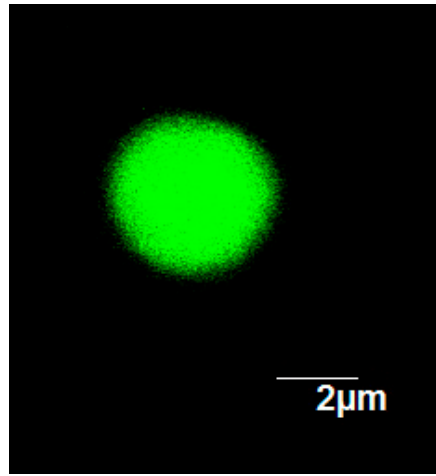

(a)

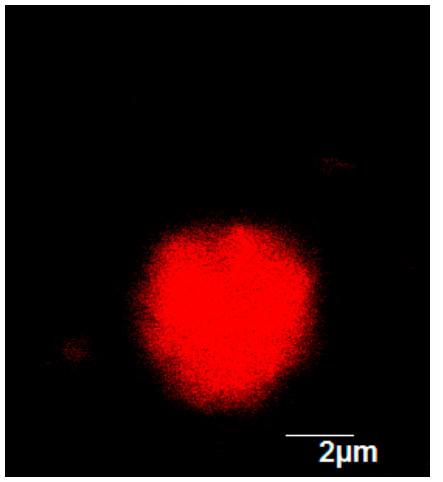

(b)

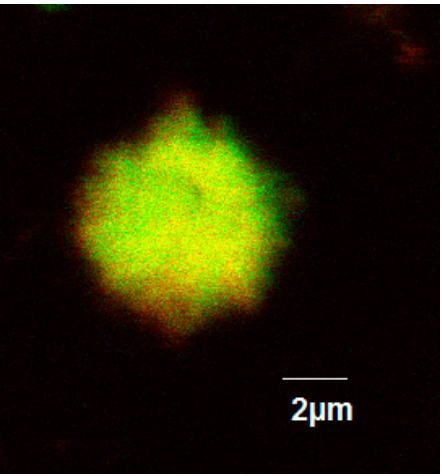

(c)

Figure 3. Confocal images. (a) SOD-ELP immobilized on HPASP (SOD-ELP@HPASP); (b) CAT-ELP immobilized on HPASP (CAT-ELP@HPASP); (c) SOD-ELP and CAT-ELP co-immobilized on HPASP (SOD-ELP/CAT-ELP@HPASP).

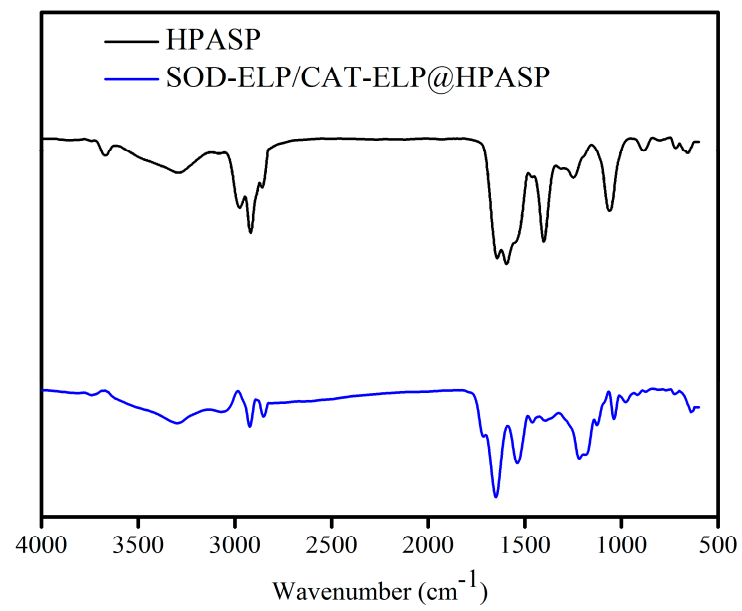

Figure 4. Fourier Transform infrared spectroscopy (FTIR) spectra. Black line: hexadecylaminemodified polyaspartic acid (HPASP); Blue line: SOD-ELP and CAT-ELP co-immobilized on HPASP (SOD-ELP/CAT-ELP@HPASP).

\subsection{Secondary Structures of Enzymes Monitored by Circular Dichroism Spectra}

The secondary structure of the enzymes after immobilization was monitored by circular dichroism (CD) spectra. Figure 5 shows the CD spectra for the mixed free enzymes SOD-ELP+CAT-ELP and the co-immobilized enzymes SOD-ELP/CAT-ELP@HPASP. For measuring the spectra of co-immobilized enzymes, the CD spectrum of HPAPS was recorded as a control. The blue line is for the mixed free enzymes, and the red line is for immobilized enzymes. The red line is close to the blue line. The mean residue ellipticity at $222 \mathrm{~nm}$ reflects the change of $\alpha$-helical content. The difference in the absorbance at $222 \mathrm{~nm}$ between the red and blue lines is very small, indicating that the two enzymes after immobilization have retained the alpha helical contents of the free enzymes. 


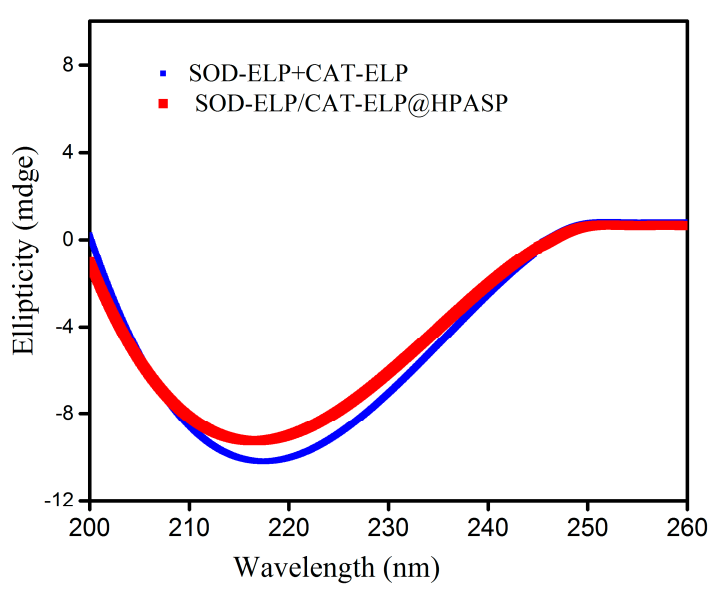

Figure 5. Circular dichroism (CD) spectra for two mixed enzymes SOD-ELP+CAT-ELP (blue) and co-immobilized enzymes SOD-ELP/CAT-ELP@HPASP (red).

\subsection{Stability of the Immobilized Enzymes against Denaturing by Urea}

Urea is commonly utilized as denaturing agent for testing the stability of proteins and enzymes [29]. Herein fluorescence spectroscopic experiments were performed to investigate the stability of the immobilized enzymes by using urea as denaturing agent. Tryptophan, tyrosine, and phenylalanine are fluorescent amino acids in proteins, and tryptophan is the dominant intrinsic fluorophore [24]. Acrylamide has been widely used to quench tryptophan fluorescence in order to investigate protein conformational change upon interfering by denaturing agents [29].

The Stern-Volmer equation $\mathrm{F}_{0} / \mathrm{F}=1+\mathrm{K}_{\mathrm{SV}}[\mathrm{Q}]$ [30] can be used to describe the concentrationdependence quenching, where $\mathrm{F}$ and $\mathrm{F}_{0}$ are the fluorescence intensities in the presence and absence of acrylamide, respectively, [Q] is the acrylamide concentration, and $\mathrm{K}_{\mathrm{SV}}$ is the Stern-Volmer quenching constant. By comparing $\mathrm{K}_{\mathrm{SV}}$ values, the information of conformational change can be obtained [31,32]. A larger $\mathrm{K}_{\mathrm{SV}}$ value means a lower stability. The Stern-Volmer plots for the enzymes were obtained (Figure 6). The $\mathrm{K}_{\mathrm{SV}}$ values for the mixed enzymes SOD-ELP+CAT-ELP and the conjugate SOD-ELP/CAT-ELP@HPASP at the urea concentration $3 \mathrm{M}$ are 2.16 and 1.68 , respectively. The $\mathrm{K}_{\mathrm{SV}}$ value of the system SOD-ELP+CAT-ELP is larger than that of SOD-ELP/CAT-ELP@HPASP at identical conditions. Compared to SOD-ELP/CAT-ELP@HPASP, SOD-ELP+CAT-ELP is more inclined to exposure of the tryptophan residues to solvent upon interfering by urea. SOD-ELP/CAT-ELP@HPASP is more resistant to the urea denaturation than SOD-ELP+CAT-ELP, indicating improved stability of the enzymes after immobilization.

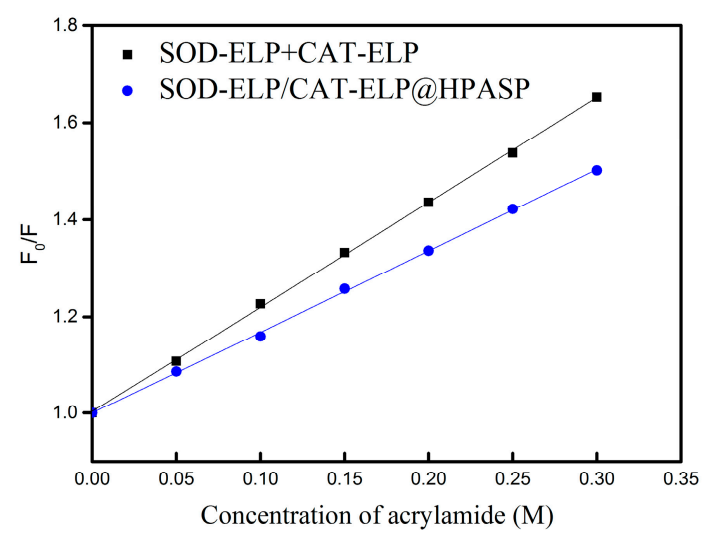

Figure 6. Stability comparison between the two mixed enzymes (SOD-ELP+CAT-ELP) and co-immobilized enzymes (SOD-ELP/CAT-ELP@HPASP). 


\subsection{Enzymatic Activity}

Pyrogallol has been well known to autoxidize rapidly [33]. Pyrogallol can autoxidize in alkaline solutions to produce superoxide an ion radical $\left(\bullet \mathrm{O}_{2}{ }^{-}\right)$. Superoxide dismutase (SOD) catalyzes the dismutation of superoxide into $\mathrm{H}_{2} \mathrm{O}_{2}$ and oxygen, thus a low level of superoxide is maintained. Here the inhibition of pyrogallol autoxidation by superoxide dismutase has been monitored for the determination of the enzymatic activity. Before testing the co-immobilized two enzymes, the activity of SOD and that of SOD-ELP was compared. Based on the UV-Vis absorption at $320 \mathrm{~nm}$ (data not shown), the superoxide anion $\left(\bullet \mathrm{O}_{2}{ }^{-}\right)$scavenging ability of SOD is comparable to that of SOD-ELP. It is demonstrated that the fusion of ELP to SOD did not have significant effect on the enzymatic activity of SOD. For co-immobilized two enzymes, The absorption increment with reaction time was plotted as shown in Figure 7a,b. The experimental data demonstrated that there were good linear relationships between the absorption at $325 \mathrm{~nm}(\mathrm{~A} 325 \mathrm{~nm})$ value and reaction time (Figure 7c). This is essential as only a linear increase is suitable for determining $\left(\bullet \mathrm{O}_{2}{ }^{-}\right)$radical-scavenging activity [33], which is defined as $(\triangle \mathrm{A} 325 \mathrm{~nm}$ control $/ \mathrm{T}-\Delta \mathrm{A} 325 \mathrm{~nm}$ enzyme $/ \mathrm{T}) / \Delta \mathrm{A} 325 \mathrm{~nm}$ control $/ \mathrm{T} \times 100 \% . \Delta \mathrm{A} 325 \mathrm{~nm}$ control is the increase in A325 nm of the mixture without enzyme and $\Delta \mathrm{A} 325 \mathrm{~nm}$ enzyme is that for the sample with enzyme, $\mathrm{T}=6 \mathrm{~min}$. Based on the results of Figure $7 \mathrm{c}$, the superoxide anion $\left(\bullet \mathrm{O}_{2}{ }^{-}\right)$ scavenging ability is $63.15 \pm 0.75 \%$ for SOD-ELP/CAT-ELP@HPASP. In a separate test, the activity of two mixed enzymes was measured (data not shown). The results by the two mixed enzymes are very close to that by co-immobilized enzymes. It is further confirmed that the immobilization has little effect on the activity of the enzymes.
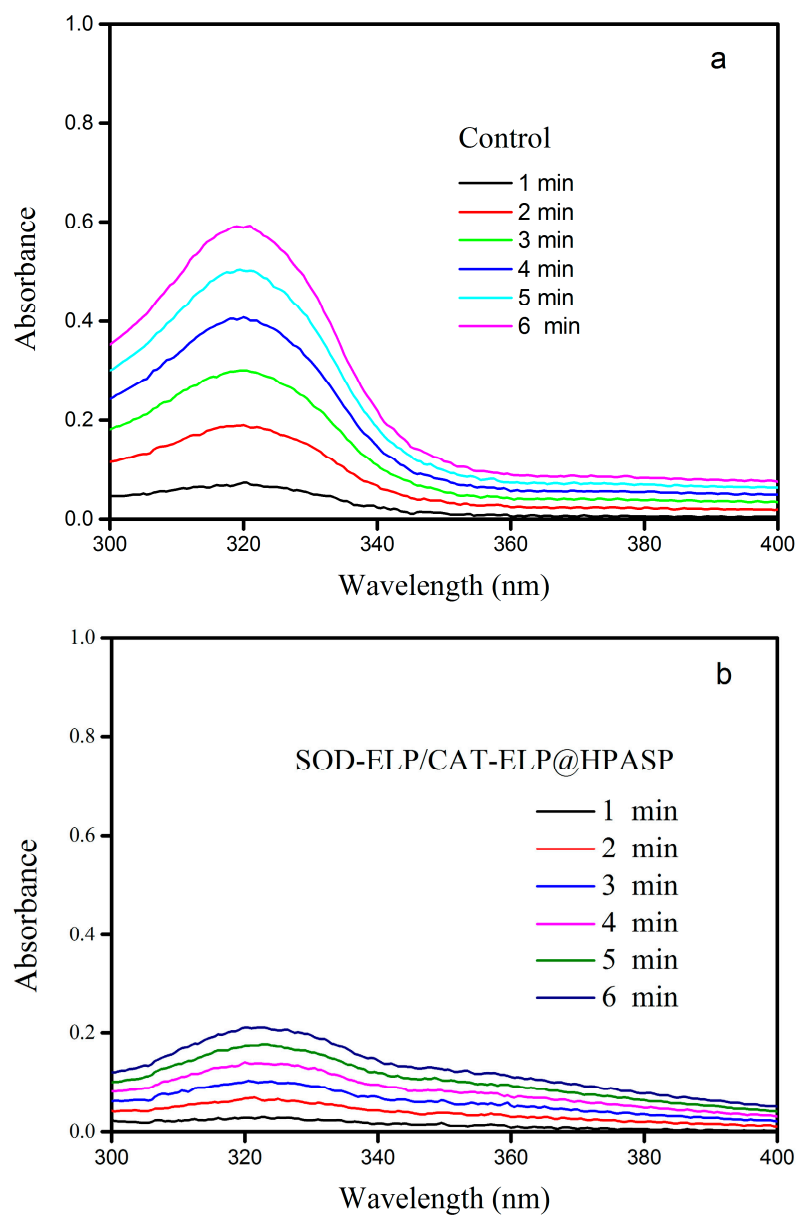

Figure 7. Cont. 


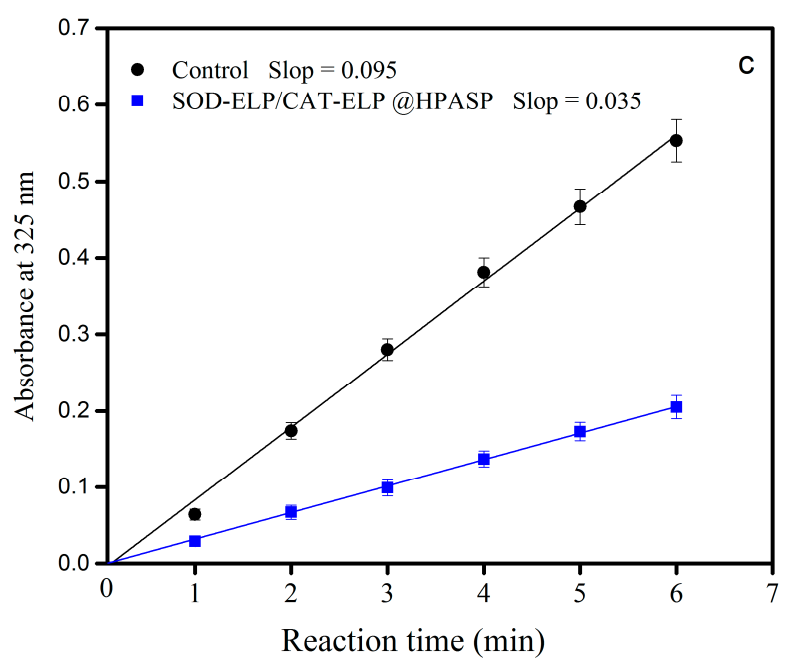

Figure 7. (a) Absorption with reaction time without enzyme; (b) Absorption with reaction time with the co-immobilized enzyme SOD-ELP/CAT-ELP@HPASP; (c) Stern-Volmer plots for the quenching of enzyme fluorescence by acrylamide. $\mathrm{F}_{0}$ and $\mathrm{F}$ are the fluorescence intensities in the absence and presence of acrylamide, respectively.

\section{Experimental Section}

\subsection{Materials}

DNA ligase, DNA polymerase, and restriction enzymes were purchased from Fermentas (Burlington, ON, Canada). The extraction kit for extracting DNA was from OMEGA (Omega Bio-tek, Guangzhou, China). The ELP monomer and oligonucleotide primers were synthesized by BGI Tech (Shenzhen, China). E. coli (Escherichia coli) strain BL21 (DE3) (Beijing University of Chemical Technology, Beijing, China) was used as a host for producing enzymes and polypeptides. All plasmid constructs were generated using standard molecular cloning techniques. The constructions of plasmids have been confirmed by DNA sequencing (BGI Tech). More description in detail for plasmid constructions have been presented in Supporting Information. SDS-PAGE analysis was performed on $12 \%$ polyacrylamide gels (Beijing University of Chemical Technology, Beijing, China). All other reagents were purchased from Sigma-Aldrich (Shanghai, China) or Sinopharm Chemical Reagent Co., Ltd. (Shanghai, China).

\subsection{Protein Expression and Purification}

The expression of enzymes is briefly described as follows [34]. E. coli BL21 harboring the plasmids were grown at $25^{\circ} \mathrm{C}$ in Luria-Bertani (LB) medium with $50 \mu \mathrm{g} / \mathrm{mL}$ Amp. After reaching an OD600 $\mathrm{nm}$ value of 0.5 , the culture was induced with $0.2 \mathrm{mM}$ IPTG. Cells were grown at $25^{\circ} \mathrm{C}$ for $8 \mathrm{~h}$. E. coli cells were harvested by centrifugation at $5000 \times g$ at $4{ }^{\circ} \mathrm{C}$ for $30 \mathrm{~min}$ and resuspended in phosphate buffer saline (PBS, $50 \mathrm{~mL}$ ). The cells were disrupted through ultrasonication on ice. Cell debris were removed by centrifugation of the lysate at $10,000 \times g$ at $4{ }^{\circ} \mathrm{C}$ for $30 \mathrm{~min}$. The supernatant was transferred to a fresh tube. Then $\mathrm{NaCl}$ solution $(3 \mathrm{M})$ was added and thoroughly mixed. The resulting sample was maintained at $30{ }^{\circ} \mathrm{C}$ for $10 \mathrm{~min}$, then centrifuged at $30{ }^{\circ} \mathrm{C}$ for $10 \mathrm{~min}$. The purification was performed in triplicate using inverse transition cycling [26].

The purified enzymes were then subjected to SDS-PAGE. Protein solution with protein amount approximately $16 \mu \mathrm{g}$ was mixed with an equal volume of SDS-PAGE loading buffer. The mixture was then heated at $96^{\circ} \mathrm{C}$ for $6 \mathrm{~min}$. The denatured proteins were separated on $12 \%$ SDS-PAGE gels at $130 \mathrm{~V} / 25 \mathrm{~mA}$ for approximately $2 \mathrm{~h}$ in SDS running buffer. 


\subsection{Co-Immobilization of SOD-ELP and CAT-ELP on HPASP}

The synthesis of hexadecylamine-modified poly(aspartic acid) (HPASP) has been described in supporting information. The co-immobilization of SOD-ELP and CAT-ELP on HPASP was carried out as follows: $100 \mathrm{mg}$ of HPASP was dispersed in MES buffer $(100 \mathrm{~mL}, \mathrm{pH}$ 6, $50 \mathrm{mM})$, and then the mixture was added to a solution of N-Hydroxysuccinimide (NHS) in MES buffer. After sonication for $10 \mathrm{~min}$, 1-ethyl-3-(3-dimethylaminopropyl) carbodiimide (EDC, $20 \mathrm{mmol} / \mathrm{L}$ ) was added. The resulting mixture was shaken at $150 \mathrm{rpm}$ for $60 \mathrm{~min}$. HPASP was activated and separated from the solution by filtering through a membrane $(0.45 \mu \mathrm{m})$, and excess NHS and EDC were removed by washing with 2-(N-morpholino)ethanesulfonic acid (MES) buffer. The separated HPASP was then transferred to the solution of SOD-ELP $(3.0 \mathrm{mg} / \mathrm{mL})$ and CAT-ELP $(3.0 \mathrm{mg} / \mathrm{mL})$ and sonicated to redisperse HPASP, followed by shaking under $120 \mathrm{rpm}$ at $4{ }^{\circ} \mathrm{C}$ for $9 \mathrm{~h}$. Then mixture was centrifuged at $4{ }^{\circ} \mathrm{C}$ for $15 \mathrm{~min}$ at $6000 \times g$, and the supernatant was removed. Five washes were carried out to remove unbound enzymes, with the addition of fresh buffer each time. The micro bicinchoninic acid (BCA) assay was used to determine the concentrations of enzymes in the solutions [35]. By measuring the concentrations of enzymes in the initial solutions, washing solutions after immobilization and supernatants, the amount of immobilized enzymes on the HPASP was finally determined. Triplicate measurements were performed to obtained average values. The amount of enzymes immobilized was finally determined to be $0.45 \pm 0.02 \mathrm{mg}$ enzymes/mg HPASP.

\subsection{Characterization}

Circular dichroism (CD) spectra were measured on a JASCO J-810 CD instrument (JASCO Corporation, Shanghai, China) to monitor the secondary structural change of the proteins. The cell length was $10 \mathrm{~mm}$ and the bandwidth was $0.5 \mathrm{~nm}$. The scan speed was set to be $50 \mathrm{~nm} / \mathrm{min}$. By dissolving the proteins in PBS buffer, the enzyme solutions were prepared. The enzyme concentrations were $0.03 \mathrm{mg} / \mathrm{mL}$. The measurements were performed at $25{ }^{\circ} \mathrm{C}$. The PBS buffer was measured and the obtained spectrum was used as control. The averaged spectra were obtained by repeating five times scan.

The FTIR spectrometer was Bruker TENSOR 27 (Bruker, Beijing, China), which was equipped with a temperature-controlled attenuated total reflectance (ATR). The detector used was a liquidnitrogen-cooled mercury-cadmium-telluride detector, collecting 128 scans per spectrum. The spectrum for the ATR element was used as the control. For purging water vapor, ultrapure nitrogen gas was introduced.

Confocal images were captured with a Leica TCS SP2 confocal microscope (Leica, Shanghai, China). The laser excitation wavelength of $488 \mathrm{~nm}$ was chosen $\left(\lambda_{\mathrm{ex}}=494 \mathrm{~nm}\right.$ and $\left.\lambda_{\mathrm{em}}=519 \mathrm{~nm}\right)$. Samples were mounted on conventional glass slides.

The size and morphology for co-immobilized enzymes was observed using scanning electron microscopy (SEM; Hitachi SU1510, Shanghai, China). The acceleration voltages used for SEM image observation was $5 \mathrm{kV}$.

\subsection{Fluorescence Measurements}

The enzymes were dissolved in PBS buffer (50 mM potassium phosphate, $\mathrm{pH}$ 7.5, urea, $2 \mathrm{mM}$ ethylenediaminetetraacetic acid (EDTA)), with enzyme concentrations $0.08 \mathrm{mg} / \mathrm{mL}$ for SOD-ELP and CAT-ELP. Urea concentrations was 3.0 M. Incubation of the samples was carried out overnight at room temperature, and equilibrium was ensured at the urea concentration. Acrylamide solutions were prepared with concentrations from 0.05 to $0.3 \mathrm{M}$. A aliquot of acrylamide solution was added to the samples $(2 \mathrm{~mL})$. After a 5 -min incubation, the solutions were subjected to emission spectra recording. F-7000 spectrophotometer (Hitachi, Shanghai, China) with a $10 \mathrm{~mm}$ path length cuvette was used to record fluorescence spectra. Using excitation wavelength $295 \mathrm{~nm}$, Tryptophan emission spectra 
were measured. Excitation and emission slits were set at $5 \mathrm{~nm}$ with a scan speed of $1200 \mathrm{~nm} / \mathrm{min}$. By subscribing the background fluorescence, fluorescence spectra were corrected.

\subsection{Enzyme Activity Analysis}

The enzyme activity of SOD was assayed as following. Three solutions were prepared. Solution A contained $1.5 \mathrm{mM}$ EDTA.2Na and $55 \mathrm{mM}$ Tris- $\mathrm{HCl}$ buffer with a $\mathrm{pH} 8$, solution B contained $0.08 \mu \mathrm{M}$ enzyme, and solution C contained $60 \mathrm{mM}$ pyrogallol and $0.015 \mathrm{M} \mathrm{HCl} .4 .0 \mathrm{~mL}$ solution A was added into two quartz cuvettes. One quartz cuvette was used for background measurement. $10 \mu \mathrm{L}$ solution $B$ was added into another quartz cuvette. Then $10 \mu \mathrm{L}$ solution $C$ was added into the quartz cuvette and rapidly shaken by hand. UV-Vis spectra (Shimadzu UV2550-PC, Shimadzu, Beijing, China) were obtained in the quartz cuvette with a $1.0 \mathrm{~cm}$ optical pathway. The absorption was measured every $60 \mathrm{~s}$ for $300 \mathrm{~s}$.

\section{Conclusions}

Hexadecylamine-modified poly(aspartic acid) (HPASP) is able to self-assemble, forming soft microparticles. The HPASP microparticles were used to co-immobilize SOD-ELP and CAT-ELP through amidation reaction. Circular dichroism (CD) confirmed that the secondary structures of the co-immobilized enzymes have been preserved. Fluorescence spectra showed that the co-immobilized enzymes exhibited a higher stability than the free enzymes. Activity assay results demonstrated that the superoxide anion $\left(\bullet \mathrm{O}_{2}{ }^{-}\right)$scavenging ability is $63.15 \pm 0.75 \%$ for the conjugate. The advantages of using HPASP to co-immobilize the two enzymes include: the soft support HPASP itself is a polypeptide in nature; the stability of immobilized enzymes is improved, and; a high activity has been achieved. Potentially SOD-ELP/CAT-ELP@HPASP can be applied in cosmetic industry.

Supplementary Materials: The following are available online at www.mdpi.com/2073-4344/7/7/217/s1, Figure S1. Analysis of purified SOD (a) and CAT (b) by SDS-PAGE. Lane M: molecular mass marker (KDa); Lane 1 is for the purified proteins. SOD: superoxide dismutase; CAT: catalase. Table S1. ELP monomer.

Acknowledgments: This work was supported by the National Science Foundation of China $(21376021,21576018)$.

Author Contributions: Wei Feng and Peijun Ji provided the idea and design for the study; Siyu Mao, Rong Li and Wenchen Wang performed the experiments and data analuysis; Siyu Mao drafted the manuscript; Wei Feng and Peijun Ji revised it.

Conflicts of Interest: The authors declare no conflict of interest.

\section{References}

1. Hu, P.; Tirelli, N. Scavenging ROS: Superoxide dismutase/catalase mimetics by the use of an oxidationsensitive nanocarrier/enzyme conjugate. Bioconj. Chem. 2012, 23, 438-449. [CrossRef] [PubMed]

2. Zhang, Q.; Tao, H.; Lin, Y.; Hu, Y.; An, H.; Zhang, D.; Feng, S.; Hu, H.; Wang, R.; Li, X.; et al. A superoxide dismutase/catalase mimetic nanomedicine for targeted therapy of inflammatory bowel disease. Biomaterials 2016, 105, 206-221. [CrossRef] [PubMed]

3. Droge, W. Free radicals in the physiological control of cell function. Physiol. Rev. 2002, 82, 47-95. [CrossRef] [PubMed]

4. Paclick, K.P.; Laroux, F.S.; Fuseler, J.; Wolf, R.E.; Gray, L.; Hoffman, J.; Grisham, M.B. Role of reactive metabolites of oxygen and nitrogen in inflammatory bowel disease. Free Radic. Biol. Med. 2002, 33, 311-322.

5. Tainer, J.A.; Getzoff, E.D.; Richardson, J.S.; Richardson, DC. Structure and mechanism of copper, zinc superoxide dismutase. Nature 1983, 306, 284-287. [CrossRef] [PubMed]

6. Perry, J.J.; Shin, D.S.; Getzoff, E.D.; Tainer, J.A. The structural biochemistry of thesuperoxide dismutases. Biochim. Biophys. Acta 2010, 1804, 245-262. [CrossRef] [PubMed]

7. Snow-Lisy, D.C.; Sabanegh, E.S.; Samplaski, M.K.; Morris, V.B.; Labhasetwar, V. Superoxide dismutase-loaded biodegradable nanoparticles targeted with a follicle-stimulating hormone peptide protect Sertoli cells from oxidative stress. Fertil. Steril. 2014, 101, 560-567. [CrossRef] [PubMed] 
8. Lacatusu, I.; Badea, N.; Badea, G.; Brasoveanu, L.; Stan, R.; Ott, C.; Oprea, O.; Meghea, A. Ivy leaves extract based-lipid nanocarriers and their bioefficacy on antioxidant and antitumor activities. RSC Adv. 2016, 6, 77243-77255. [CrossRef]

9. Caddeoa, C.; Manconi, M.; Fadda, A.M.; Lai, F.; Lampis, S.; Diez-Sales, O.; Sinico, C. Nanocarriers for antioxidant resveratrol: Formulation approach, vesicle self-assembly and stability evaluation. Colloids Surf. B Biointerfaces 2013, 111, 327-332. [CrossRef] [PubMed]

10. Bhushan, B.; Gopinath, P. Antioxidant nanozyme: A facile synthesis and evaluation of the reactive oxygen species scavenging potential of nanoceria encapsulated albumin nanoparticles. J. Mater. Chem. B 2015, 3, 4843-4852. [CrossRef]

11. Rosenbaugh, E.G.; Roat, J.W.; Yang, R.F.; Manickam, D.S.; Yin, J.X.; Schultz, H.D.; Bronich, T.K.; Batrakova, E.V.; Kabanov, A.V.; Zucker, I.H.; et al. The attenuation of central angiotensin II-dependent pressor response and intra-neuronal signaling by intracarotid injection of nanoformulated copper/zinc superoxide dismutase. Biomaterials 2010, 31, 5218-5226. [CrossRef] [PubMed]

12. Manickam, D.S.; Brynskikh, A.M.; Kopanic, J.L.; Sorgen, P.L.; Klyachko, N.L.; Batrakova, E.V.; Bronich, T.K.; Kabanov, A.V. Well-defined cross-linked antioxidant nanozymes for treatment of ischemic brain injury. J. Control. Release 2012, 162, 636-645. [CrossRef] [PubMed]

13. Perriotte-Olson, C.; Adi, N.; Manickam, D.S.; Westwood, R.A.; Desouza, C.V.; Natarajan, G.; Crook, A.; Kabanov, A.V.; Saraswathi, V. Nanoformulated Copper/zinc Superoxide Dismutase Reduces Adipose Inflammation in Obesity. Obesity 2015, 24, 148-156. [CrossRef] [PubMed]

14. Corvo, M.L.; Jorge, J.C.; van't Hof, R.; Cruz, M.E.; Crommelinc, D.J.; Stormc, G. Superoxide dismutase entrapped in long-circulating liposomes: Formulation design and therapeutic activity in rat adjuvant arthritis. Biochim. Biophys. Acta 2002, 1564, 227-236. [CrossRef]

15. Corvo, M.L.; Martins, M.B.; Francisco, A.P.; Morais, J.G.; Cruz, M.E. Liposomal formulations of Cu, Zn-superoxide dismutase: Physico-chemical characterization and activity assessment in an inflammation model. J. Control. Release 1997, 43, 1-8. [CrossRef]

16. Regnault, C.; Roch-Arveiller, M.; Tissot, M.; Sarfati, G.; Giroud, J.P.; Postaire, E.; Hazebroucq, G. Effect of encapsulation on the anti-inflammatory properties of superoxide dismutase after oral administration. Clin. Chim. Acta 1995, 240, 117-127. [CrossRef]

17. Rengel, R.G.; Barišić, K.; Pavelić, Z.; Grubišić, T.Z.; Čepelak, G.I.; Filipović-Grčić, J. High efficiency entrapment of superoxide dismutase into mucoadhesive chitosan-coated liposomes. Eur. J. Pharm. Sci. 2002, 15, 441-448. [CrossRef]

18. Veronese, F.M.; Largajolli, R.; Boccu, E.; Benassi, C.A.; Schiavon, O. Surface modification of proteins-Activation of monomethoxy-polyethylene glycols by phenylchloroformates and modification of ribonuclease and superoxide-dismutase. Appl. Biochem. Biotechnol. 1985, 11, 141-152. [CrossRef] [PubMed]

19. Beckman, J.S.; Minor, R.L.; White, C.W.; Repine, J.E.; Rosen, G.M.; Freeman, B.A. Superoxide-dismutase and catalase conjugated to polyethylene-glycol increases endothelial enzymeactivity and oxidant resistance. J. Biol. Chem. 1988, 263, 6884-6892. [PubMed]

20. Beauchamp, C.O.; Gonias, S.L.; Menapace, D.P.; Pizzo, S.V. A new procedure for the synthesis of polyethylene glycolprotein adducts-Effects on function, receptor recognition, and clearance of superoxide-dismutase, lactoferrin, and alpha-2-macroglobulin. Anal. Biochem. 1983, 131, 25-33. [CrossRef]

21. Muizelaar, J.P.; Marmarou, A.; Young, H.F.; Choi, S.C.; Wolf, A.; Schneider, R.L.; Kontos, H.A. Improving the outcome of severe head-injury with the oxygen radical scavenger polyethylene glycol-conjugated superoxide-dismutase-A phase-II trial. J. Neurosurg. 1993, 78, 375-382. [CrossRef] [PubMed]

22. Caliceti, P.; Schiavon, O.; Morpurgo, M.; Veronese, F.M.; Sartore, L.; Ranucci, E.; Ferruti, P. Physicochemical and biological properties of monofunctional hydroxy terminating poly(nvinylpyrrolidone) conjugated superoxide-dismutase. J. Bioact. Compat. Polym. 1995, 10, 103-120. [CrossRef]

23. Yi, X.A.; Zimmerman, M.C.; Yang, R.F.; Tong, J.; Vingoradow, S.; Kabanov, A.V. Pluronic-modified superoxide dismutase 1 attenuates angiotensin ii-induced increase in intracellular superoxide in neurons. Free Radic. Biol. Med. 2010, 49, 548-558. [CrossRef] [PubMed]

24. Pastor, I.; Esquembre, R.; Micol, V.; Mallavia, R.; Mateo, C.R. A ready-to-use fluorimetric biosensor for superoxide radical using superoxide dismutase and peroxidase immobilized in sol-gel glasses. Anal. Biochem. 2004, 334, 335-343. [CrossRef] [PubMed] 
25. Giovagnoli, S.; Luca, G.; Casaburi, I.; Paolo, B.; Macchiarulo, G.; Ricci, M.; Calvitti, M.; Basta, G.; Calafiore, R.; Rossi, C. Long-term delivery of superoxide dismutase and catalase entrapped in poly(lactide-co-glycolide) microspheres: In Vitro effects on isolated neonatal porcine pancreatic cell clusters. J. Control. Release 2005, 107, 65-77. [CrossRef] [PubMed]

26. Meyer, D.E.; Chilkoti, A. Genetically encoded synthesis of protein-based polymers with precisely specified molecular weight and sequence by recursive directional ligation: Examples from the elastin-like polypeptide system. Biomacromolecules 2002, 3, 357-367. [CrossRef] [PubMed]

27. Kolling, O. Re-examination of the effect of aprotic solvents upon the fundamental vibrational peak of the carbonyl group in 1,1,3,3-tetramethylurea. Appl. Spectrosc. 1999, 53, 29-32. [CrossRef]

28. Daud, F.N.; Ahmad, A.; Badri, K.H. An investigation on the properties of palm-based polyurethane solid polymer electrolyte. Int. J. Polym. Sci. 2014, 2014, 1-5. [CrossRef]

29. Arroyo, M.; Menéndez, M.; García, J.L.; Campillo, N.; Hormigo, D.; de la Mata, M.; Castillón, P.; Acebal, C. The role of cofactor binding in tryptophan accessibility and conformational stability of His-tagged D-amino acid oxidase from Trigonopsis variabilis. Biochim. Biophys. Acta 2007, 1774, 556-565. [CrossRef] [PubMed]

30. Merrill, A.R.; Palmer, L.R.; Szabo, A.G. Acrylamide quenching of the intrinsic fluorescence of tryptophan residues genetically engineered into the soluble colicin $\mathrm{E} 1$ channel peptide. Structural characterization of the insertion-competent state. Biochemistry 1993, 32, 6974-6981. [CrossRef] [PubMed]

31. Shu, Y.; Liu, M.; Chen, S.; Chen, X.; Wang, J. New insight into molecular interactions of imidazolium ionic liquids with bovine serum albumin. J. Phys. Chem. B 2011, 115, 12306-12314. [CrossRef] [PubMed]

32. Georlette, D.; Blaise, V.; Bouillenne, F.; Damien, F.; Thorbjarnardottir, S.H.; Depiereux, E.; Gerday, C.; Uversky, V.H.; Feller, G. Adenylation-dependent conformation and unfolding pathways of the $\mathrm{NAD}^{+}$-dependent DNA ligase from the thermophile Thermus scotoductus. Biophys. J. 2004, 86, 1089-1104. [CrossRef]

33. Li, X. Improved pyrogallol autoxidation method: A reliable and cheap superoxide-scavenging assay suitable for all antioxidants. J. Agric. Food Chem. 2012, 60, 6418-6424. [CrossRef] [PubMed]

34. Du, K.; Zhao, J.; Sun, J.; Feng, W. Specific Ligation of Two Multimeric Enzymes with Native Peptides and Immobilization with Controlled Molar Ratio. Bioconj. Chem. 2017, 28, 1166-1175. [CrossRef] [PubMed]

35. Smith, P.K.; Krohn, R.I.; Hermanson, G.T.; Mallia, A.K.; Gartner, F.H.; Provenzano, M.D.; Fujimoto, E.K.; Goeke, N.M.; Olson, B.J.; Klenk, D.C. Measurement of protein using bicinchoninic acid. Anal. Biochem. 1985, 150, 76-85. [CrossRef] 